\title{
New insights into the application of geographical information systems and remote sensing in veterinary parasitology
}

\author{
Laura Rinaldi ${ }^{1}$, Vincenzo Musella ${ }^{1}$, Annibale Biggeri ${ }^{2}$, Giuseppe Cringoli ${ }^{1}$ \\ ${ }^{1}$ Dipartimento di Patologia e Sanità Animale, Università degli Studi di Napoli "Federico II”, Napoli, \\ Italy; ${ }^{2}$ Dipartimento di Statistica "G. Parenti”, Università di Firenze, Firenze, Italy
}

\begin{abstract}
Over the past 10-15 years, significant advances have been made in the development and application of geographical information systems (GIS) and remote sensing (RS). In veterinary sciences, particularly in veterinary parasitology, GIS and RS offer powerful means for disease mapping, ecological analysis and epidemiological surveillance and have become indispensable tools for processing, analysing and visualising spatial data. They can also significantly assist with the assessment of the distribution of health-relevant environmental factors via interpolation and modelling. In this review, we first summarize general aspects of GIS and RS, and emphasize the most important applications of these tools in veterinary parasitology, including recent advances in territorial sampling. Disease mapping, spatial statistics, including Bayesian inference, ecological analyses and epidemiological surveillance are summarized in the next section and illustrated with a set of figures. Finally, a set of conclusions is put forward.
\end{abstract}

Keywords: Geographical information systems, remote sensing, disease mapping, spatial statistics, veterinary parasitology.

\section{Introduction}

Application of geographical information systems (GIS) and remote sensing (RS) in veterinary and human medical sciences, particularly in veterinary and human parasitology, is rapidly advancing. During the past 10-20 years the publication of original research articles and reviews in veterinary and human health with an emphasis on GIS and/or RS has followed an exponential trend (Hendrickx et al., 2004). In addition, recent GIS/RS symposia organized at national and international conferences, and several thematic issues on this topic published in the peer-reviewed international literature (e.g. special theme issues in Advances in Parasitology in 2000

Corresponding author:

Giuseppe Cringoli

Dipartimento di Patologia e Sanità Animale

Facoltà di Medicina Veterinaria

Università degli Studi di Napoli “Federico II"

Via della Veterinaria,1- 80137 Napoli, Italy

Tel. +39081 2536283; Fax +39081 2536282

E-mail: cringoli@unina.it

website: www.parassitologia.unina.it and Parassitologia in 2005) demonstrate the wide array of applications and benefits of these tools (Cringoli et al., 2005b). Furthermore, the raised interest about these new technologies is testified by the publication of thematic books pertaining GIS and RS, as well as international peer-reviewed journals, including the current launch of Geospatial Health.

The establishment and maintenance of websites as a platform for sharing data, exchanging opinions, experiences and expertise on GIS and RS with an emphasis on animal and public health is also worth mentioning (e.g.http://www.gnosisgis.org; http:// www.gisvet.org).

In this review, we first summarize general aspects of GIS and RS, and emphasize the most important applications of these tools in veterinary parasitology, including recent advances in territorial sampling. Disease mapping, spatial statistics, including Bayesian inference, ecological analyses and epidemiological surveillance are summarized in the next section and illustrated with a set of figures. Finally, a set of conclusions is put forward. 


\section{Brief history of GIS and RS}

Depending upon the application area, a number of discordant definitions of GIS have appeared in the literature (Tim, 1995). One of the most widely used definition of GIS is that proposed by Burrough (1986), i.e. "a powerful set of tools for collecting, retrieving at will, transforming, and displaying spatial data from the real world". Overall, a GIS is a platform consisting of hardware, software, data and people and encompasses a fundamental and universally applicable set of value-added tools for capturing, transforming, managing, analyzing, and presenting information that are geographically referenced (geo-referenced).

Digital GIS data may be presented in map form using so called data layers representing the information collected. Two approaches can be used, namely (i) a vector data model and (ii) a raster data model. The former model stores a table containing coordinates of points together with instructions on which points are alone and which points belong to a common set. In a vector data model, all lines are represented by chains of vectors, and all areas by polygons (Fig. 1). Attributes are coded in separate tables using alphanumeric characters as a label for a specific class or category of properties. The raster data model uses a net of adjacent polygons (termed "cells") to provide a virtual cover of a given part of a territory. The cells are often called pixels, and attribute-values of the objects that the cells represent are assigned to corresponding pixels (Daniel et al., 2004). Raster data are typically utilized to represent continuous phenomena, e.g. land cover maps, digital elevation models and phenoclimatic maps (Fig. 2).

The use of GIS in epidemiology can aid in answering some important questions such as "what is?" and "where is?". In addition, because also the time domain - i.e. "when" - is important in most environmental and epidemiological processes, it has also been suggested that GIS should be replaced by STIS, which is an abbreviation for space-time information systems (Kistemann et al., 2002; Hendrickx et al.,

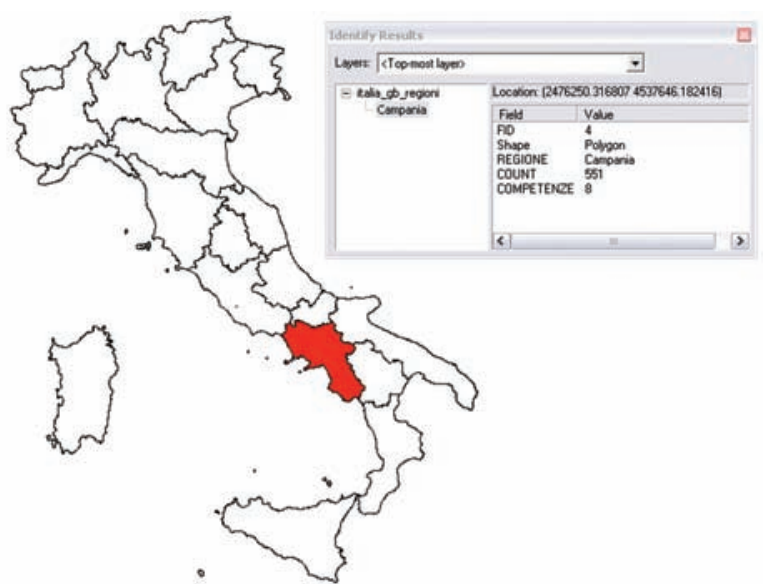

Fig. 1. Vector map of Italy and attribute (spreadsheet), used in this example to extract the Campania region.

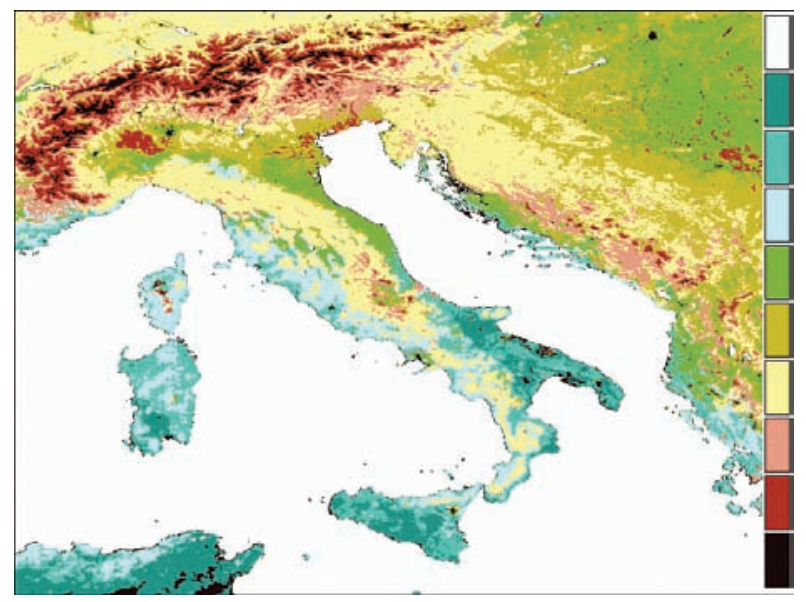

Fig. 2. Raster map of southern Italy, pheno-climatic map.

2004). There is currently a movement towards regarding GIS as a science (geographical information science) rather than a simple technology (Goodchild, 2000; Kistemann et al., 2002).

One of the first major uses for GIS was in 1964 when the Canadian Geographical Information System (CGIS) was launched in an effort to assess the productivity of Canadian farmland.

Subsequently, GIS has become widely and effectively used in natural-resource management. Prominent examples are timber management, mine permitting, water quality assessment, wildlife and habitat management, land use planning, zoning, and 
transportation design; predictive modelling of earthquakes, forest fires, and flooding; utilities management, routing analysis; marketing and demographic analyses, etc. (Cox and Gifford, 1997).

The capacity of these systems justifies their wider application including veterinary and human medical sciences.

Several types of analyses routinely used in GIS can be very useful for spatial epidemiology. These include (i) neighbourhood analysis, i.e. all features which meet certain criteria and are adjacent to a particular feature are found and listed, (ii) buffer generation, i.e. generation of buffer zones around or along certain features, (iii) overlay analysis, i.e. merging of two or more layers or maps to identify areas of intersection, (iv) network analysis, i.e. modelling of networks and calculation of parameters such as the shortest distance between two locations, (v) surface area and distance calculations and (vi) three-dimensional surface modelling (Ward and Carpenter, 2000).

A very useful function of GIS is the kriging, i.e. a linear interpolation method that predicts the values of a variable, at non-sampled locations, based on observations at known locations, using a model of the covariance of a random function (Berke, 2004). Kriging is widely used in meteorology in order to interpolate values of climate data from observing stations, and have also been used in veterinary epidemiology to model the distribution of various parasites/diseases, e.g. Ixodes scapularis that transmits Lyme disease (Nicholson and Mather, 1996), malaria (Kleinschmidt et al., 2000), alveolar echinococcosis (Conraths et al., 2003; Pleydell et al., 2004), tsetse flies that transmit human African trypanosomiasis (Sciarretta et al., 2005), Calicophoron daubneyi, the causative agent of paramphistomosis in ruminants (Biggeri et al., 2004), Oncomelania hupensins, the intermediate host snail of Schistosoma japonicum (Zhang et al., 2005), as well as co-infection with $S$. mansoni and hookworm among schoolchildren in Côte d'Ivoire (Raso et al., 2006).

The term "remote sensing" (RS) was used - for the first time - in the US during the 1960s to designate the technique allowing the study of objects without any direct contact, through image capture. In 1970, in an article titled "New eyes for epidemiologists: aerial photography and other remote sensing techniques" Cline recognised that RS could have applications in detecting and monitoring disease outbreaks. In the following year, scientists of the National Aeronautics and Space Administration (NASA) in the US, used colour infrared aerial photography to identify the habitats of Aedes sollecitans (Hay, 2000).

While aerial photographs were the first source of RS data, the subsequent development of satellite measuring instruments significantly improved both the spatial and temporal coverage of the earth surface, generating a continuous and almost complete cover. Satellites may be divided into two groups based on the orbit they follow, namely (i) geostationary satellites (e.g. GOES, Meteosat, GMS) and (ii) near-polar-orbiting (or sun-synchronous) satellites (e.g. NOAA, Landsat, MODIS, SPOT, IKONOS, Quickbird). The former group, which consists of satellites in orbits parallel with the rotation of the earth, is dedicated to meteorological applications, while the latter follows an elliptical orbit between 681 and $915 \mathrm{~km}$, with a different ground track after each rotation, lasting about 100 minutes. The revisit period varies from 1 to 41 days but can be lowered. Most of the satellites are sunsynchronous and offer different spatial resolutions (Herbreteau et al., 2005). However, very few have found any application in epidemiology, the most important being the Landsat and the NOAA series (Durr and Gatrell, 2004).

Satellites have several sensors recording radiation in different wavelengths that allow combination of spectral signals (Cringoli et al., 2005a; de La Rocque et al., 2005). RS provides a unique source of data that can be exploited to characterize climate and land surface variables at different spatial resolutions. It permits the calculation of vegetation indices, land surface temperatures, atmospheric and soil moisture, rainfall indices, etc. Among the vegetation indices obtained from RS, the most widely 
employed one is the normalized difference vegetation index (NDVI). It is defined as the difference between the visible (red) and near-infrared (nir) bands of satellite information over their sum: NDVI $=($ nir - red $) /($ nir + red $)$. NDVI is a specific measure of chlorophyll abundance and light absorption, but its use has been extended to quantify herbaceous vegetation biomass, vegetation primary productivity, vegetation coverage and phenology.

The RS data are increasingly used for investigations in the field of environmental health sciences for mapping and prediction, surveillance and monitoring, particularly for vector-borne diseases (Beck et al., 2000). Since the disease vectors have specific requirements regarding climate, vegetation, soil and other edaphic factors, and are sensitive to changes in these factors, RS can be used to determine their present and future and predict distribution.

Land cover classification refers to the natural vegetative cover, function of the topography, soil or local climate, and can differentiate between different covers up to the species communities. Land use classification refers to the description of human uses of the land, or immediate actions modifying the land cover, such as agriculture (e.g. used for crop production, lying fallow, irrigated, etc.), human settlements (e.g. urban, rural, isolated infrastructures, etc.), protected areas (e.g. national parks, forest reserves, etc.) (for recent reviews see Daniel et al., 2004 and Herbreteau et al., 2005). In Europe, the corine (Coordination of Information on the Environment) land cover (CLC, European Commission, 2000) is widely used, which is a map of the European environmental landscape based on interpretation of satellite images. CLC provides comparable digital maps of land cover for each country for much of Europe. It is useful for environmental analysis and comparisons over large scales (spatial resolution $=1 \mathrm{~km}$ ).

When studies are focused on small areas, aerial photographs can be used because of their capability to afford very high spatial resolution images $(<1 \mathrm{~m})$. The analysis of historical sequences of aerial photographs is an important method for determining the medium-term dynamics of land cover on a landscape scale (Acosta et al., 2005).

Most developed and developing countries have governmental programmes for aerial surveys but campaigns are not reproduced on a regular time basis, and ground coverage is often limited to areas of discreet interest. However, aerial photography must be considered as a supplementary source of information (Herbreteau et al., 2005). Classifications of landscape from digital aerial photographs have been scarcely used in veterinary parasitology, with the majority of applications focusing on mosquito surveillance (see for example, Kline and Wood, 1988, Brown and Sethi, 2002). Fig. 3 reports an example of classification of landscape by interpretation of aerial photographs.

\section{Disease mapping}

One of the most useful functions of GIS in epidemiology continues to be its utility in basic mapping. Usually, when data are collected either routinely or through purposely-designed surveys, they are presented in tabular forms, which can be exploited for analytical usage. However, the reading and interpretation of such data is often a laborious and time-consuming task and does not permit easy decision-making (Paolino et al., 2005). On the other hand, representation of these data in the form of a map facilitates interpretation, synthesis and recognition of frequency and clusters of phenomena.

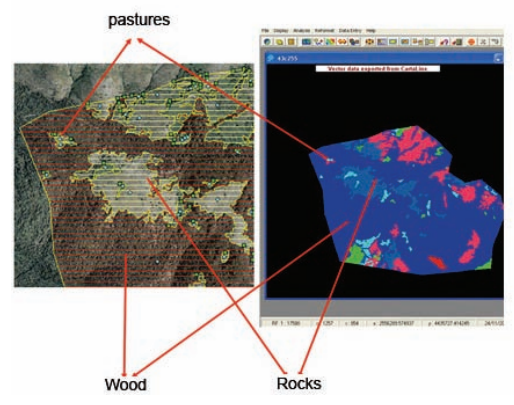

Fig. 3. Example of classification of landscape from digital aerial photographs. 
The oldest examples date back more than 200 years and consist of a world map of diseases put forward by Finke in 1792 (Barrett, 2000), and a map of yellow fever occurrences in the harbour of New York issued in 1798 (Stevenson, 1965). One of the most prominent examples is the mapping of cholera victims in relation to the location of water supplies in London's Soho district carried out by John Snow (1854). The street addresses of cholera victims were recorded and close proximity to putative pollution sources (i.e. water supply pumps) was identified as the key risk factor.

With respect to parasites, in two papers published in 1903, Smith and Stiles independently presented maps of Texas, which displayed the prevalence of hookworm infection and demonstrated that infection was typically restricted to the eastern part of the state where the soils contain the most sand (Brooker and Michael, 2000).

Disease maps can be drawn to a demographic base or to a geographic base. In the first case, they are related to the population and the epidemiological information they show are presented in relation to population size. Geographically based maps are constructed according to the shape of a country or a region or any administrative unit. They may be qualitative e.g. point maps, distribution maps, point distribution maps (PDMs, Fig. 4), indicating location without specifying the amount of disease; or quantitative e.g. distribution maps with proportioned peaks (Fig. 5), proportional circle maps, choroplethic maps (Fig. 6), choroplethic maps with proportioned peaks, PDMs with proportioned peaks, PDMs with proportioned circles (Fig. 7a), isoplethic maps, displaying the number of cases of disease, the population at risk, infection prevalence or intensity or incidence (Thrusfield, 1995; Cringoli et al., 2005c). With the appropriate data at hand, producing a map using GIS can be undertaken literally in a matter of minutes; but therein lies one of the problems with GIS - one needs the spatiallyexplicit data - and collecting these may take months or even years (Durr, 2004). GIS is, however, not only a digital map representation but is indeed an

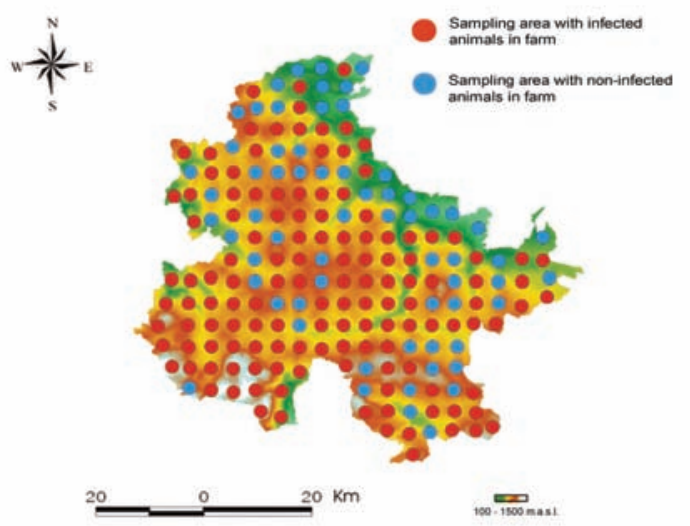

Fig. 4. Point distribution map. Dicrocoelium dendriticum in sheep from an area of the southern Italian Apennines (from Cringoli et al., 2002).

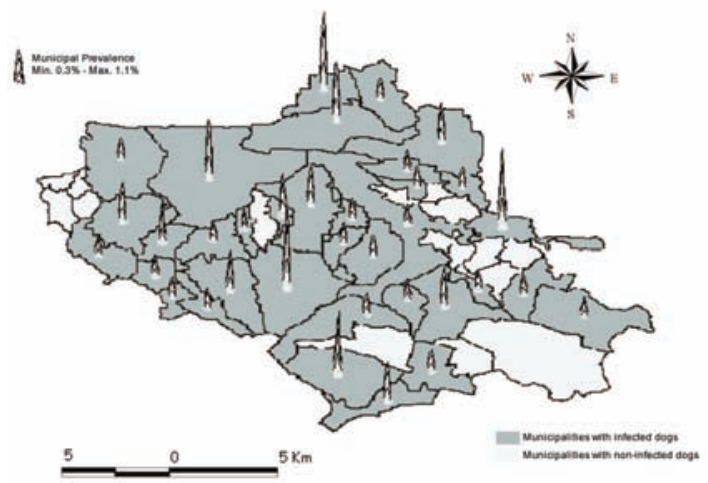

Fig. 5. Distribution map with proportioned peaks. Dipetalonema reconditum in dogs from the Mt. Vesuvius area of southern Italy (from Cringoli et al., 2001).

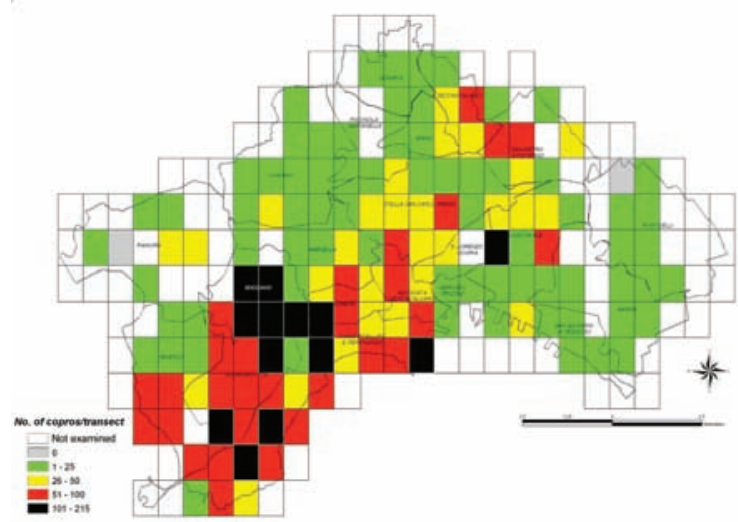

Fig. 6. Choroplethic map. Canine fecal contamination in Naples (Campania region, southern Italy), February-May, 2005 . 


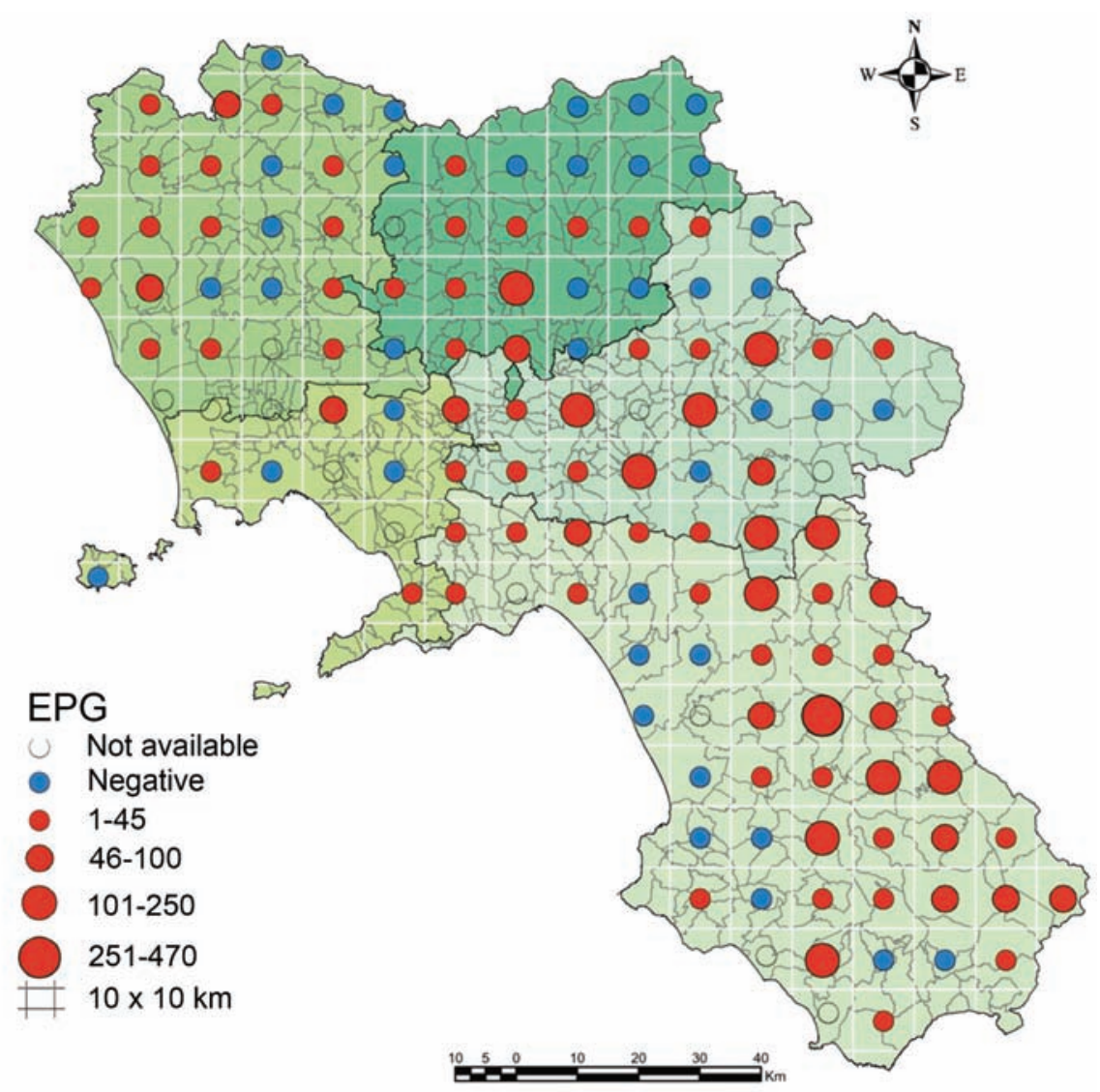

Fig. 7. Dicrocoelium dendriticum in sheep from the Campania region of southern Italy. Point Distribution Map with proportioned circles.

information and analysing tool which permits the processing of space-related data. Certainly, maps themselves keep on playing a prominent role and are, of course, the most frequently used output of GIS (Kistemann et al., 2002). For spatial epidemiology, GIS has become an important tool for designing a study, territorial sampling, and the drawing of maps.

The fundamental steps which can be used to produce quality descriptive disease maps within GIS are the following:

(i) selection of the study area;

(ii) selection of the study population and calculation of the sample size, using as parameters the study population, the expected prevalence, the confidence level, and the standard error;

(iii) selection of the sample in the study area (e.g. random sampling, systematic sampling, proportional allocation, use of grids, etc.);

(iv) laboratory and/or field survey;

(v) geo-referencing of the study units (e.g. farms, counties, municipalities, regions, or any other administrative unit); and finally

(vi) drawing maps by GIS (Cringoli et al., 2005c).

The sampling procedures in the study area play obviously a key role in disease mapping. As indicated at point 3 above, several sampling methods can be used. For parasites connected to the landscape (e.g. soil-transmitted helminths or trematodes that require a snail as intermediate host), the grid approach 
(measured on the sample size) seems to be useful in order to produce usable point density maps (Cringoli et al., 2002) without need for further interpolation or extrapolation (Hendrickx et al., 2004).

GIS can also be used to do transect sampling when non-moving objects are to be counted, which involves the choosing of a line or series of lines along which the counts are to be made. This approach has been used by us in order to study canine faecal contamination in the city of Naples (southern Italy). Fig. 8 is an example of a transect drawn on a digital aerial photograph using GIS (Biggeri et al., 2006b).

The information derived from descriptive maps provides an operational tool for planning, monitoring and managing control programmes, and for deriving inferences about the relationship between the environment and diseases. In fact, without good descriptive maps of disease agent/vector species' distribution, based on ground observation, we do not have the essential starting point to generate predictive maps based on statistical pattern-matching (Randolph, 2000).

\section{Spatial statistics}

The term "spatial statistics" refers to the collection of statistical methods in which spatial location plays an important role in the study design or data analysis (Diggle, 2004). While developments in spatial statistics within the human health sciences have advanced considerably, there has been less evidence of a corresponding interest in such methodology within veterinary medicine. This may partly be due to the greater funding and focus in the scientific community on human health (Lawson and Zhou, 2005). In addition, the linkage between statistical methods and GIS has been poorly developed and even today only few spatial statistical extensions are available (e.g. Geostatistical Analyst and Spatial Analyst) within commercially available GIS platforms. An alternative may be to export spatial data from GIS to spatial statistical software (for a com- plete list of software, see Ward and Carpenter, 2000; Durr et al., 2004).

A framework of spatial statistic of epidemiological data includes data visualization, exploratory analysis and modelling (Pfeiffer, 2004). With respect to data visualization, maps based on raw data are generally unstable since the observed differences in disease occurrence between areas are difficult to interpret, as they emanate from the sum of true, structural differences and of the noise derived from the sampling process. This problem is well known in human epidemiology, and several statistical analyses have been proposed to filter the signal from the noise (Elliot et al., 2000). Some of these techniques have been also used in veterinary medicine, e.g. regarding fasciolosis (Durr et al., 2005), paramphistomosis (Biggeri et al., 2005), echinococcosis

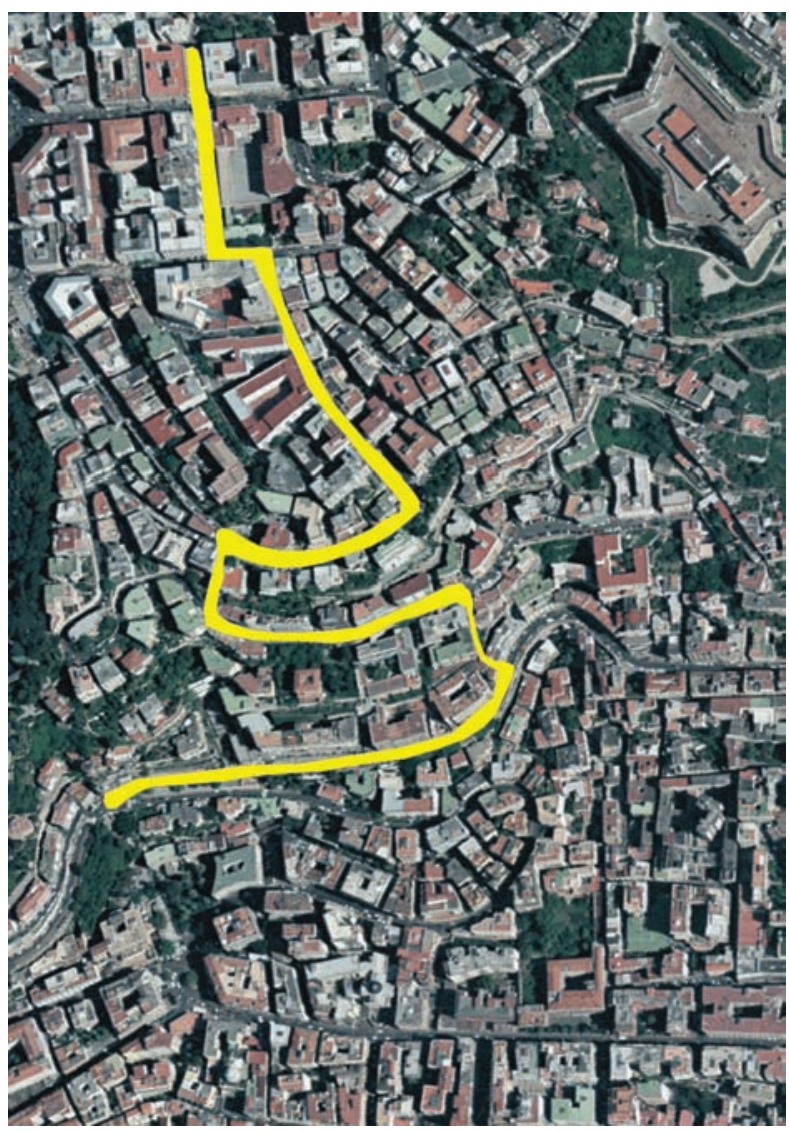

Fig. 8. Transect on a digital aerial photo (from Biggeri et al., 2006b). 
(Berke, 2001; Budke et al., 2005), bovine spongiform encephalopathy (Abrial et al., 2005), mastitis (Green et al., 2004), and foot and mouth disease (Lawson and Zhou, 2005). Recently we also used these techniques for Dicrocoelium dendriticum (Biggeri et al., 2006a).

Exploratory analysis refers to describe patterns in the distribution of a disease of interest and possibly discriminate between systematic and random fluctuations. Several tests have been proposed and are based on different assumptions about data generating mechanism and level of analysis (on aggregate measure or point locations). To provide a few examples from a long list on spatial data, the presence of structured variability on aggregate data can be detected using autocorrelation indices (Moran's I or Smans' D); on point data in the form of a case-control sampling design, the Cuzick-and-Edwards' test (Cuzick and Edwards, 1990) can be used to detect general clustering, and the spatial scan statistic can be applied to both kinds of data to detect clusters of disease. With regard to temporal data, assuming population homogeneity, the Ederer-Myers test (Ederer et al., 1964) can be employed, as well as Mantel's proposal (Mantel et al., 1976) for general clustering. The temporal scan statistic can be utilized for identifying time clusters and the Knox test can be used also to test for time-space clusters of disease cases.

Time-series analysis has a long tradition in the literature. Statistical modelling can be used to study patterns within the series or association between dependent and independent variables over time (Ward and Carpenter, 2000). Veterinary applications of space and time cluster detection methods have been reviewed by Ward and Carpenter (2000) and Pfeiffer (2004).

Modelling of spatial data aims to explain or predict the occurrence of disease. Various static or dynamic relationships defined by the underlying models are used to derive new output maps from a set of input maps. Predictive maps can be obtained following heuristic algorithms (like a neural network), standard frequentist approaches (extensions of regression modelling, linear discriminant analysis in case of multivariate data, or a generalized linear mixed model in case of an unmeasured source of variability), or Bayesian approaches to derive predictive distributions taking into account related uncertainty. For the latter, Markov chain Monte Carlo (MCMC) techniques have become a popular way to approximate Bayesian posterior distributions. A review of Bayesian statistics for parasitologists is available from the literature (Basáñez et al., 2004) and a paper, published in this issue of Geospatial Health presents an innovative Bayesian application using both stationary and non-stationary models for malaria risk mapping (Gosoniu et al., 2006).

\section{Ecological analysis}

Ecological analysis is targeted on the description of relations existing between the geographic distribution of diseases and environmental risk factors and their analysis by means of statistical procedures (Kistemann et al., 2002). A wide number of papers have been published on the analysis of the relationship between disease indicators (e.g. positivity, incidence and prevalence) and the explanatory environmental and climatic variables (Herbreteau et al., 2005). In order to make ecological analysis, the following fundamental steps can be utilized:

(i) GIS construction for the study area utilizing data layers on environmental and climatic features;

(ii) geo-referencing the geographic units of interest, e.g. farms, centroids of the main pastures, etc.;

(iii) creation of buffer zones of a given diameter centered on these geo-referenced points;

(iv) extrapolation of values for each environmental feature within each buffer zone;

(v) databases with environmental and parasitological data;

(vi) statistical analyses (univariate, multivariate, etc.) and individualize of environmental risk factors and/or development of forecast models (Cringoli et al., 2005c; Rinaldi et al., 2005). 
A part from the administrative boundaries, the data layers on environmental and climatic features most commonly used for ecological analysis in veterinary epidemiology are: NDVI, land cover and land use, elevation, slope, aspect, lithofacies map, presence of lakes, rivers and other water bodies, temperatures, rainfall and humidity (for an example, see Fig. 9).
The extrapolation of environmental variables can also be directly extracted from the study units instead of the buffer zones. But usually, once these data layers are obtained, the ecological analysis is made by the association between the disease data and the environmental characteristics extracted within buffer zones constructed around the geographic unit of interest (Cringoli et al., 2004;
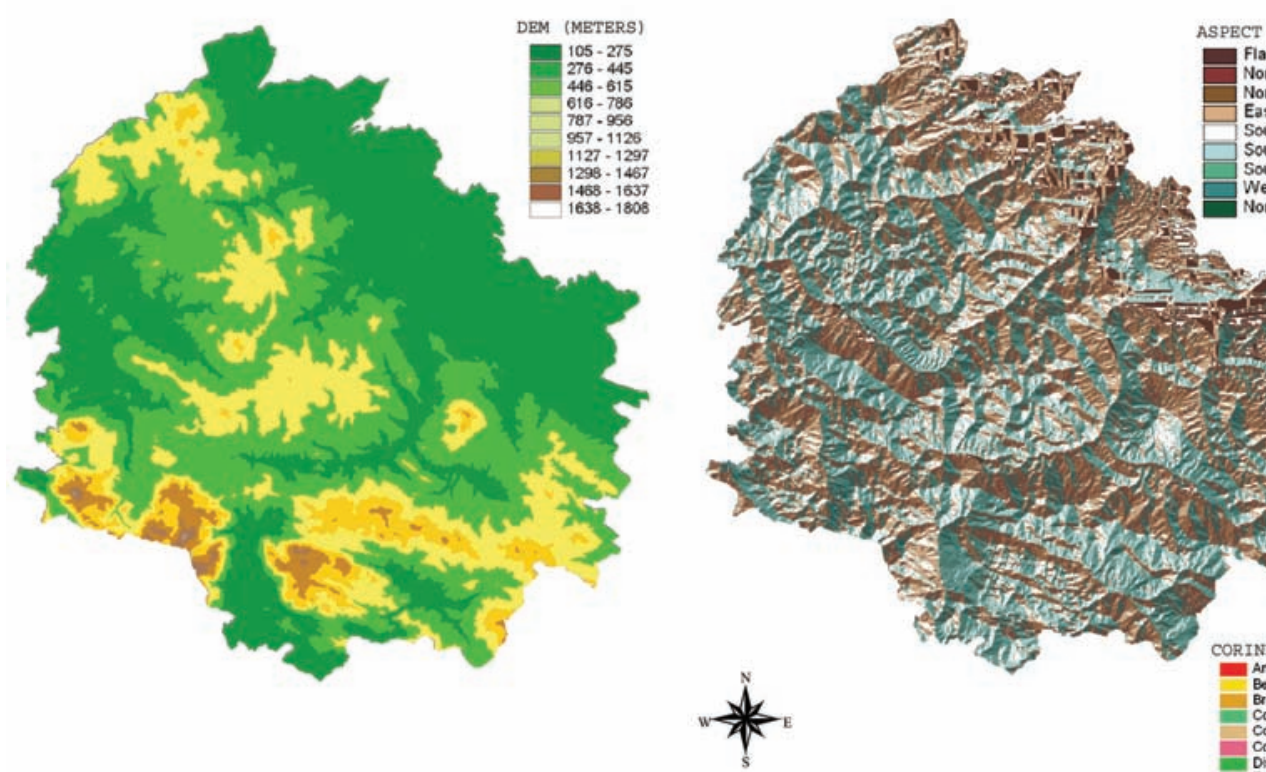

SPECT OF DEM (DEGREES) Flat $(-1)$ North $(0-22.5 .337 .5-360$
Northeast $(22.5-67.5)$ East (67.5-112.5) Southeast $(1125-157.5$ South (157.5-2025) Southwest $(202.5-247.5$ West $(247.5-292.5)$ Northwest $(292.5-337.5)$
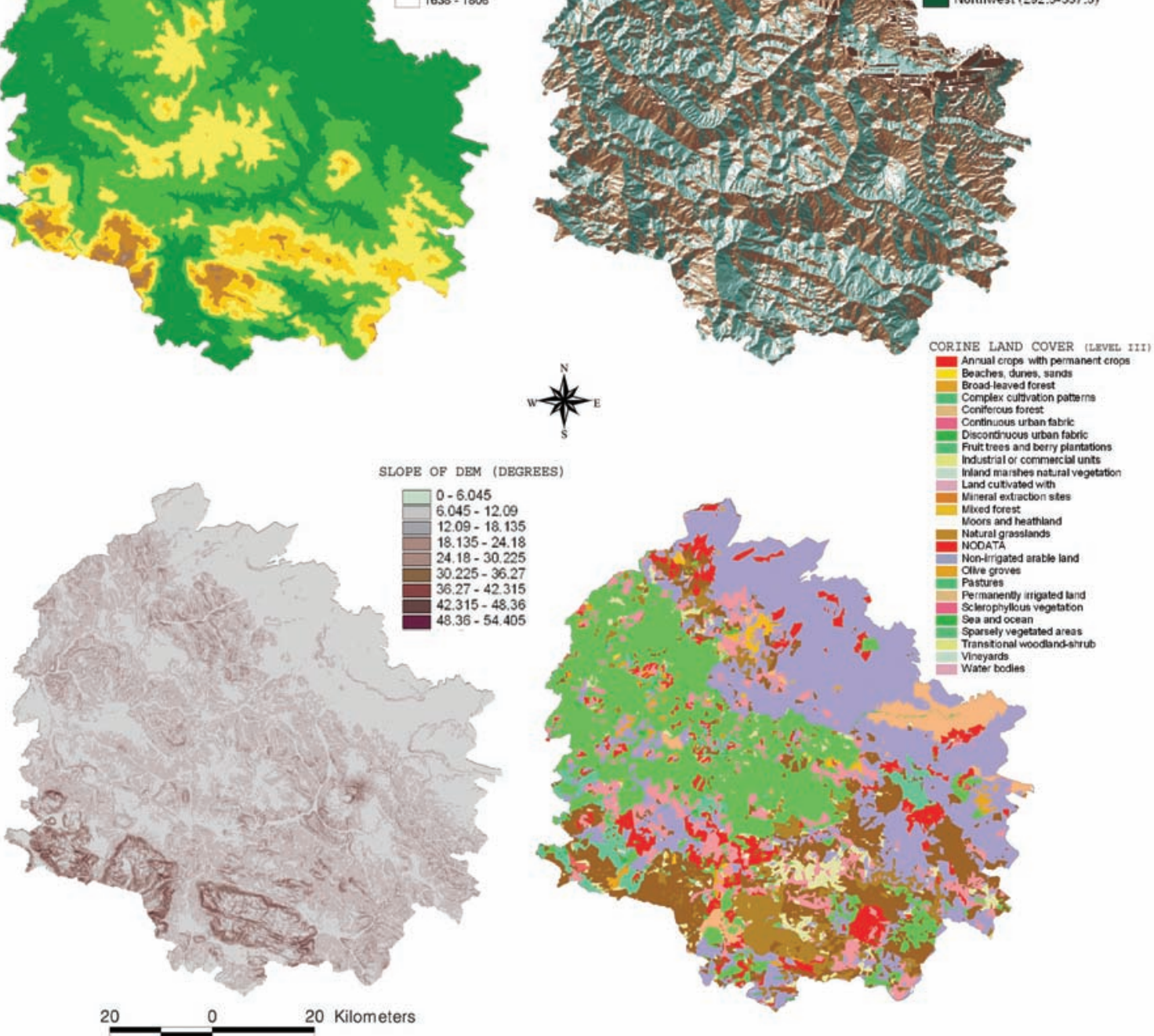

Fig. 9. Data layers used for ecological analysis: a) elevation; b) aspect; c) slope; d) land cover (from Rinaldi et al., 2005). 
Rinaldi et al., 2005). Generally speaking, the smaller the area in which disease and environmental data are collected, the greater the possibility to make accurate inferences, because averages over large areas can introduce strong ecological bias in correlation studies with disease occurrence data. For example, for a parasitological disease bound to the pasture, the extrapolation of climatic and environmental data for buffer zones may lead to the inclusion of unsuitable values of a certain variable in the ecological analysis. For this reason, in our recent study on sheep helminths, we chose to delimit the pasture areas of the animals on aerial photographs, including only the values of climatic and environmental variables falling into such pasturing areas in the ecological analysis (Fig. 10).

GIS and RS can be also used to predict disease seasonality based on the climatic and/or environmental characteristics of a certain area and the information about the climatic and/or environmental requirement(s) of a certain species. Climate-based forecast systems, employing the concept of growing degree days (GDD), have been developed for different diseases of veterinary importance, such as fasciolosis,

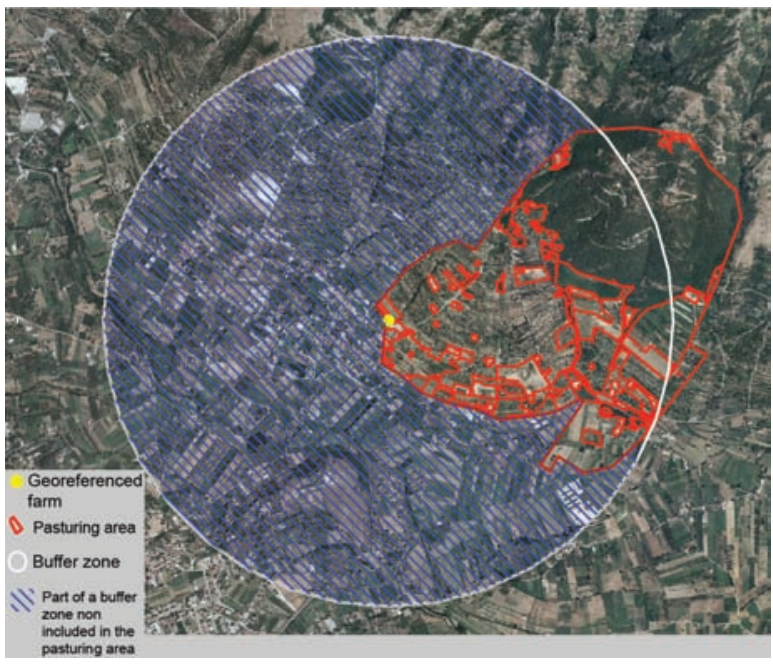

Fig. 10. Comparison between a buffer zone and a delimitation of the pasture from which the environmental data can be obtained.

schistosomosis and malaria (Malone, 2005), as well as dirofilariosis (Genchi et al., 2005) (Fig. 11). These predictions can be extremely useful in decision-support for disease intervention.

Moreover, a recent publication suggests that estimation of GDD over an entire year can be utilized

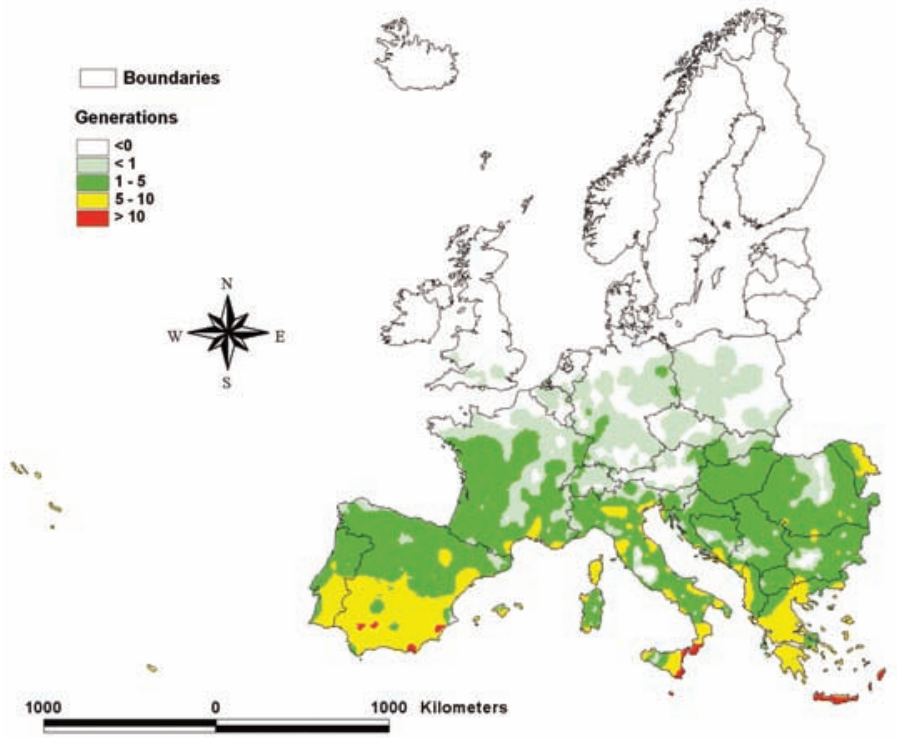

Fig. 11. Predictive model based on growing degree days. Yearly average predicted number of Dirofilaria immitis generations in Europe (from Genchi et al., 2005). 
for present and future predictions of schistosomiasis transmission in China in the context of regional climate change (Yang et al., 2006)

\section{Epidemiological surveillance in veterinary medicine}

Disease monitoring and control in veterinary medicine consist in a series of activities that are often the object of specific national or international normative. Within this framework, epidemiological surveillance implies the quantification of disease occurrence and, eventually, field studies followed by specific laboratory investigations and case characterization. A surveillance system is characterized by an integrated set of planned epidemiological activities whose aim is to identify and prevent new cases of disease. Such a system is justified provided the natural history of the disease and its determinants are known and effective preventive strategies are available.

A basic requirement is the capability to transfer information of a new case of disease in the population under surveillance. Traditionally, data flows are activated by specific laws and are dealth with by specialized agencies set up to conduct epidemiological surveys after alert. The timeliness in reporting, sensitivity and specificity of the system are critical. Where the rapidity of reporting is of primary importance, the surveillance system has peculiar characteristics and the main goal is to identify as soon as possible new cases of disease or variation on the "natural" rate of occurrence.

In any event, a surveillance system has peculiar characteristics independent from the techniques used to collect cases of disease. This aspect becomes evident when considering the geographical dimension of the phenomenon and the surveillance aims to monitor discontinuities in the rate of disease in space. The process that generates cases of disease is heterogeneous, i.e. the frequency of disease is not uniform over the map but proportional to the number of people at risk. This implies a considerable challenge in interpreting clusters of cases of disease and in attributing them to an epidemic, or a modifi- cation in the occurrence of disease. For example, the clustering could be simply the consequence of the non-homogeneous population density (Elliott et al., 1992; Aylin et al., 1999)

Geographical surveillance screens for the presence of non-natural clusters of disease in space. The system require setting up a GIS which stores the characteristics of the territory. It is important to collect spatial data relevant to the phenomenon to be monitored. Recent innovative data gathering relates to satellite images and aerial photographs, and the availability of geo-referenced population at risk or a sample of it (Kreiger et al., 2005). This last feature requires an efficient system to geo-reference the unit-at-risk and to update the GIS over time. Geo-referenced data by the traditional use of global positioning system (GPS) is expensive and less precise than alternative techniques based on aerial photographs (Cringoli et al., unpublished data).

Once the spatial distribution of the population at risk is available, there is a need to collect information on the "natural" rate of occurrence of the phenomenon under study. The following describes two possible extreme situations. First, the relevant information could be obtained from the available literature under the assumption that the "natural" rate of disease be constant over the territory under surveillance. This approach, of course, requires access to a literature database and the capability to perform a critical appraisal of the available evidence. Indeed, quality and reliability of scientific information depend on the study design, techniques of data collection and analysis, as well as characteristics of the studied populations. Such information cannot always be immediately extended to the particular context of the local surveillance system. Second, educated guesses and estimates might be available with regard to the "normal" disease risk under "normal" conditions. In terms of GIS surveillance this would produce a statistical estimate (and its standard error) of the frequency of the disease and become the reference rate to evaluate any subsequent emergence of disease cases. 
In both situations, and in any practical situation, the system has to produce a statistical estimate of the expected number of cases under "normal" conditions. The surveillance system can be viewed as an expert system in which the reference information to make any decision is represented by the map of the expected cases. Such a map can serve as the benchmark for impact assessment or decision processes in case of changes in the phenomenon under study. However, appropriate statistical modelling is needed. The system will assist in evaluating spontaneous claims or data arising from routine scan - by law. In this case the decision concerns the interpretation of cluster of observed cases faced against the expected number of cases at a given location of the territory.

To conclude, a geographical surveillance epidemiological system is composed by:

(i) knowledge of the natural history of the disease;

(ii) availability of effective preventive actions;

(iii) presence of an information system to readily detect new cases of disease;

(iv) set up of a GIS and the acquisition of satel lite images and ecological indexes;

(v) availability of aerial photography;

(vi) geo-referencing of population at risk;

(vii) statistical modelling and mapping of expected number of cases;

(viii) the skills needed to retrieve and critically appraise the scientific literature.

\section{Conclusions}

The trends over the past two decades and their effects in the fields of hardware, software and network technology, in particular in the internet domain, have created the prerequisites for a broad acceptance of GIS and RS within the health sciences, including veterinary science.

Recent studies showed that GIS - in addition to their broad utility reviewed here - holds promise in capturing data on medicine usage (Ryan et al., 2005), as well as in organizing spatial information involving the distinction of anatomic relationships (Ganai et al., 2006). However, epidemiology remains the main application field of GIS in veterinary and public health and, since epidemiology is inextricably bound to "place", it seems reasonable to expect that GIS will further advance as science (Jacquez, 2000). Perhaps one of the most powerful benefits of GIS is its ability to integrate different databases into a single environment. In effect, a GIS may be though of as a database of databases (Cox and Gifford, 1997).

The use of GIS, however, does by no means overcome the two major concerns of any empirical research: data availability and data quality (Kistemann et al., 2002). This issue should always be kept in mind by all GIS/RS users.

\section{References}

Abrial D, Calavas D, Jarrige N, Ducrot C, 2005. Poultry, pig and the risk of BSE following the feed ban in France-a spatial analysis. Vet Res 36, 615-628.

Acosta A, Carranza ML, Giancola M, 2005. Landscape change and ecosystem classification in a municipal district of a small city (Isernia, Central Italy). Environ Monit Assess 108, 323-335.

Aylin P, Maheswaran R, Wakefield J, Cockings S, Jarup L, Arnold R, Wheeler G, Elliott P, 1999. A national facility for small area disease mapping and rapid initial assessment of apparent disease clusters around a point source: the UK Small Area Health Statistics Unit. J Public Health Med 21, 289-298.

Barrett FA, 2000. Finke's 1792 map of human diseases: the first world disease map? Soc Sci Med 50, 915-921.

Basáñez MG, Marshall C, Carabin H, Gyorkos T, 2004. Bayesian statistics for parasitologists. Trends Parasitol 20, 85-91.

Beck LR, Lobitz BM, Wood BL, 2000. Remote sensing and human health: new sensors and new opportunities. Emerg Infect Dis 6, 217-227.

Berke O, 2001. Choropleth mapping of regional count data of Echinococcus multilocularis among red foxes in Lower Saxony, Germany. Prev Vet Med 52, 119-131. 
Berke O, 2004. Exploratory disease mapping: kriging the spatial risk function from regional count data. Int $\mathrm{J}$ Health Geog 26, 18-36.

Biggeri A, Catelan D, Dreassi E, Lagazio C, Cringoli G, 2004. Statistical models for spatial analysis in parasitology. Parassitologia 46, 75-78.

Biggeri A, Catelan D, Dreassi E, Lagazio C, Rinaldi L, Cringoli G, 2006a. Multivariate spatially structured variability of ovine parasitic infections. Paper accepted for the International Workshop on Spatio-Temporal Modelling, Pamplona, Spain 27-29th, September 2006.

Biggeri A, Catelan D, Rinaldi L, Dreassi E, Lagazio C, Cringoli G, 2005. Statistical modelling of the spatial distribution of prevalence of Calicophoron daubneyi infection in sheep from central Italy. Parassitologia 47, 157-163.

Biggeri A, Dreassi E, Catelan D, Rinaldi L, Lagazio C, Cringoli G, 2006b. Disease mapping in veterinary epidemiology: a Bayesian geostatistical approach. Stat Methods Med Res 15, 337-352.

Brooker S, Michael E, 2000. The potential of geographical information systems and remote sensing in the epidemiology and control of human helminth infections. Adv Parasitol 47, 246-279.

Brown CB, Sethi RA, 2002. Mosquito abundance is correlated with cliff swallow (Petrochelidon pyrrhonota) colony size. J Med Entomol 39, 115-120.

Budke CM, Jiamin Q, Craig PS, Torgerson PR, 2005. Modeling the transmission of Echinococcus granulosus and Echinococcus multilocularis in dogs for a high endemic region of the Tibetan plateau. Int J Parasitol 35, 163170.

Burrough PA, 1986. Principles of Geographical Information Systems for Land Resources Assessment. Clarendon, Oxford.

Cline BL, 1970. New eyes for epidemiologists: aerial photography and other remote sensing techniques. Am J Epidemiol 92, 85-89.

Conraths FJ, Staubach C, Tackmann K, 2003. Statistics and sample design in epidemiological studies of Echinococcus multilocularis in fox populations. Acta Trop 85, 183-189.

Cox AB, Gifford F, 1997. An overview to Geographic Information Systems. JAL 11, 449-461.

Cringoli G, Ippolito A, Taddei R, 2005a. Advances in satellite remote sensing of pheno-climatic features for epidemi- ological applications. Parassitologia 47, 51-62.

Cringoli G, Malone JB, Rinaldi L, 2005b. Guest editors' preface. Parassitologia 47, 3-4.

Cringoli G, Rinaldi L, Veneziano V, Capelli G, 2001. A prevalence survey and risk analysis of filariosis in dogs from the Mt. Vesuvius area of southern Italy. Vet Parasitol 102, 243-252.

Cringoli G, Rinaldi L, Veneziano V, Capelli G, Malone JB, 2002. A cross-sectional coprological survey of liver flukes in cattle and sheep from an area of the southern Italian Apennines. Vet Parasitol 108, 137-143.

Cringoli G, Rinaldi L, Veneziano V, Musella V, 2005c. Disease mapping and risk assessment in veterinary parasitology: some case studies. Parassitologia 47, 9-25.

Cringoli G, Taddei R, Rinaldi L, Veneziano V, Musella V, Cascone C, Sibilio G, Malone JB, 2004. Use of remote sensing and geographical information systems to identify environmental features that influence the distribution of paramphistomosis in sheep from the southern Italian Apennines. Vet Parasitol 122, 15-26.

Cuzick J, Edwards R, 1990. Spatial clustering for inhomogeneous populations. J R Stat Ser B 52, 73-104.

Daniel M, Kolar J, Zeman P, 2004. GIS tools for tick and tick-borne disease occurrence. Parasitology 129 (Suppl.), S329-352.

de La Rocque S, Michel JF, Bouyer J, De Wispelaere G, Cuisance D, 2005. Geographical information systems in parasitology: a review of potential applications using the example of animal trypanosomosis in West Africa. Parassitologia 47, 97-104.

Diggle PJ, 2004. Spatial Statistics in the Biomedical Sciences: Future Directions. In: Durr P and Gatrell A, editors. GIS and Spatial Analysis in Veterinary Science. CABI Publishing, 97-118.

Durr P, 2004. Spatial epidemiology and animal disease: introduction and overview. In: Durr P and Gatrell A, editors. GIS and Spatial Analysis in Veterinary Science. CABI Publishing, 35-67.

Durr PA, Gatrell AC, 2004. The tools of spatial epidemiology: GIS, Spatial Analysis and Remote Sensing. In: Durr P and Gatrell A, editors. GIS and Spatial Analysis in Veterinary Science. CABI Publishing, 1-33.

Durr PA, Tait N, Lawson AB, 2005. Bayesian hierarchical modelling to enhance the epidemiological value of abattoir 
surveys for bovine fasciolosis. Prev Vet Med 71, 157-172.

Durr P, Tait N, Staubach C, 2004. Resource Guide: Software, Data and GisVet Web. In: Durr P and Gatrell A, editors. GIS and Spatial Analysis in Veterinary Science. CABI Publishing, 285-298.

Ederer F, Myers MH, Mantel N, 1964. A statistical problem in space and time: do leukaemia cases come in clusters? Biometrics 20, 626-638.

Elliott P, Wakefield J, Best N, Briggs D, 2000. Spatial Epidemiology - Methods and Applications, Oxford University Press.

Elliott P, Westlake AJ, Hills M, Kleinschmidt I, Rodrigues L, McGale P, Marshall K, Rose G, 1992. The Small Area Health Statistics Unit: a national facility for investigating health around point sources of environmental pollution in the United Kingdom. J Epidemiol Community Health 46, 345-349.

European Commission (DG Agri EUROSTAT, Joint Research Centre (Ispra) e European Environmental Agency), 2000. From Land Cover to landscape diversity in the European Union.

Ganai S, Garb JL, Kanumuri P, Rao RS, Alexander AI, Wait $R, 2006$. Mapping the rectum: spatial analysis of transanal endoscopic microsurgical outcomes using GIS technology. J Gastrointest Surg 10, 22-31.

Genchi C, Rinaldi L, Cascone C, Mortarino M, Cringoli G, 2005. Is heartworm disease really spreading in Europe? Vet Parasitol 133, 137-148.

Goodchild MF, 2000. Communicating geographic information in a digital age. Ann Assoc Am Geogr 90, 344-355.

Gosoniu L, Vounatsou P, Sogoba N, Smith T (2006). Bayesian modelling of geostatistical malaria risk data. Geospatial Health 1 (present issue).

Green MJ, Burton PR, Green LE, Schukken YH, Bradley AJ, Peeler EJ, Medley GF, 2004. The use of Markov chain Monte Carlo for analysis of correlated binary data: patterns of somatic cells in milk and the risk of clinical mastitis in dairy cows. Prev Vet Med 64, 157-174.

Hay SI, 2000. An overview of remote sensing and geodesy for epidemiology and public health application. Adv Parasitol 47, 1-35.

Hendrickx G, Biesemans J, de Deken R, 2004. The use of GIS in veterinary parasitology. In: Durr P and Gatrell A, editors. GIS and Spatial Analysis in Veterinary Science. CABI
Publishing, 145-176.

Herbreteau V, Salem G, Souris M, Hugot JP, Gonzalez JP, 2005. Sizing up human health through remote sensing: uses and misuses. Parassitologia 47, 63-79.

Jacquez G, 2000. Spatial analysis in epidemiology: Nascent science or a failure of GIS? J Geog Sys 2, 91-97.

Kistemann T, Dangendorf F, Schweikart J, 2002. New perspectives on the use of Geographical Information Systems (GIS) in environmental health sciences. Int J Hyg Environ Health 205, 169-181.

Kleinschmidt I, Bagayoko M, Clarke GP, Craig M, Le Sueur D, 2000. A spatial statistical approach to malaria mapping. Int J Epidemiol 29, 355-361.

Kline DL, Wood JR, 1988. Habitat preference of coastal Culicoides spp. at Yankeetown, Florida. J Am Mosq Control Assoc 4, 456-465.

Krieger N, Chen JT, Waterman PD, Rehkopf DH, Subramanian SV, 2005. Painting a truer picture of US socioeconomic and racial/ethnic health inequalities: the Public Health Disparities Geocoding Project. Am J Public Health 95, 312-323.

Lawson AB, Zhou H, 2005. Spatial statistical modeling of disease outbreaks with particular reference to the UK foot and mouth disease (FMD) epidemic of 2001. Prev Vet Med 71, 141-156.

Malone JB, 2005. Biology-based mapping of vector-borne parasites by geographic information systems and remote sensing. Parassitologia 47(1), 27-50.

Mantel N, Kryscio RJ, Myers MN, 1976. Tables and formulas for extended use of the Ederer-Myers-Mantel diseaseclustering procedure. Am J Epidemiol 104, 576-584.

Nicholson MC, Mather TN, 1996. Methods for evaluating Lyme disease risks using geographic information systems and geospatial analysis. J Med Entomol 33, 711-720.

Paolino L, Sebillo M, Cringoli G, 2005. Geographical information systems and on-line GIServices for health data sharing and management. Parassitologia 47, 171-175.

Pfeiffer DU, 2004. Geographical Information Science and Spatial Analysis in Animal Health. In: Durr P and Gatrell A, editors. GIS and Spatial Analysis in Veterinary Science. CABI Publishing, 119-144.

Pleydell DR, Raoul F, Tourneux F, Danson FM, Graham AJ, Craig PS, Giraudoux P, 2004. Modelling the spatial distribution of Echinococcus multilocularis infection in foxes. 
Acta Trop 91, 253-265.

Randolph SE, 2000. Ticks and tick-borne disease systems in space and from space. Adv Parasitol 47, 217-243.

Raso G, Vounatsou P, Singer BH, N'Goran EK, Tanner M, Utzinger J, 2006. An integrated approach for risk profiling and spatial prediction of Schistosoma mansoni-hookworm co-infection. Proc Natl Acad Sci USA 103, 6934-6939.

Rinaldi L, Fusco G, Musella V, Veneziano V, Guarino A, Taddei R, Cringoli G, 2005. Neospora caninum in pastured cattle: determination of climatic, environmental, farm management and individual animal risk factors using remote sensing and geographical information systems. Vet Parasitol 128, 219-230.

Ryan K, Norris P, Becket G, 2005. Capturing data on medicines usage: the potential of community pharmacy databases. N Z Med J 118, U1677.

Sciarretta A, Girma M, Tikubet G, Belayehun L, Ballo S, Baumgartner J, 2005. Development of an adaptive tsetse population management scheme for the Luke community, Ethiopia. J Med Entomol 42, 1006-1019.

Smith AJ, 1903. Uncinariasis in Texas. Am J Med 126, 768-798.

Snow J, 1854. On the Mode of Communication of Cholera. $2^{\text {nd }}$ Ed. Churchill Livingstone, London.

Stevenson L, 1965. Putting disease on the map: the early use of spot maps in the study of yellow fever. J Hist Med Allied Sci 20, 226-261.

Stiles CW, 1903. Report upon the prevalence and geographic distribution of hookworm disease (uncinariasis or anchylostomiasis) in the United States. Hyg Lab Bull 10, 1-10.

Thrusfield M, 1995. Veterinary Epidemiology. Blackwell, London, UK.

Tim US, 1995. The application of GIS in environmental health sciences: opportunities and limitations. Environ Res 71, 75-88.

Ward MP, Carpenter TE, 2000. Techniques for analysis of disease clustering in space and in time in veterinary epidemiology. Prev Vet Med 45, 257-284.

Yang GJ, Gemperli A, Vounatsou P, Tanner M, Zhou XN, Utzinger J, 2006. A growing degree-days based time-series analysis for prediction of Schistsoma japonicum transmission in Jiangsu province, China. Am J Trop Med Hyg 75, 549-555. Zhang ZY, Xu DZ, Zhou XN, Zhou Y, Liu SJ, 2005. Remote sensing and spatial statistical analysis to predict the distribution of Oncomelania hupensis in the marshlands of China. Acta Trop 96, 205-212. 